\title{
Student Satisfaction with Online Learning: Is it a Psychological Contract?
}

\author{
Charles Dziuban, Patsy Moskal, Jessica Thompson, Lauren Kramer, \\ Genevieve DeCantis, and Andrea Hermsdorfer \\ Research Initiative for Teaching Effectiveness \\ University of Central Florida
}

\begin{abstract}
The authors explore the possible relationship between student satisfaction with online learning and the theory of psychological contracts. The study incorporates latent trait models using the image analysis procedure and computation of Anderson and Rubin factors scores with contrasts for students who are satisfied, ambivalent, or dissatisfied with their online learning experiences. The findings identify three underlying satisfaction components: engaged learning, agency, and assessment. The factor score comparisons indicate that students in the general satisfaction categories characterize important differences in engaged learning and agency, but not assessment. These results lead the authors to hypothesize that predetermined, but unspecified expectations (i.e., psychological contracts) for online courses by both students and faculty members are important advance organizers for clarifying student satisfaction.
\end{abstract}

\section{Introduction}

From its inception, online learning has been confronted by concerns about quality from the established educational community and society at large (Carnaghan \& Webb, 2007; Akdemir \& Koszalka, 2008). Often, in addressing these concerns students' perceptions of their course experience becomes a surrogate for learning engagement in the context of satisfaction (Swan, 2001; Arbaugh, 2001; Richardson \& Swan, 2003; Bolliger, 2004). Because contemporary students view information as a commodity which can be traded openly among a community of learners, collaboration becomes fundamental to a variety of educational outcomes (Shirky, 2010; Dziuban et al., 2013). 
Modern technologies are contributing to the dissolution of traditional classroom boundaries (Shirky, 2008). Students connect with their instructors and each other through modalities of almost every variety, greatly expanding avenues of communication. Norberg, Dziuban and Moskal's (2011) development of a time-based blended learning model, for instance, modifies the instructor's role (Liu \& Hwang, 2010) in learning environments based on students' synchronous and asynchronous learning preferences. The need for new and more authentic assessment techniques in addition to challenges to traditional educational structures (e.g. semester length time boundaries) raises issues about what moderates students' academic expectations and satisfaction.

Studies suggest that online students wish to decrease their ambivalence toward formal education by gaining some sense of a carefully delineated path to success (Dziuban \& Dziuban, 1998; Dziuban, Moskal \& Dziuban, 2000; Long, 2011; Young \& Dziuban, 2000). Students prefer active, rather than passive learning environments, and, because they participate in a highly interactive world, they expect the same in their classes (Dziuban et al., 2003). Today's learners require more outlets for creativity and collaboration which online learning environments can accommodate through a variety of instructional models that are provided anytime, anyplace.

Researchers should not be surprised that identifying the defining elements for satisfaction has become much more dynamic and complex. The construct has multiple facets that tend to be stochastic as a particular course progresses. In this study, we attempt to clarify the underlying (latent) elements of student satisfaction in the context of overall course evaluation for students who respond positively to online experiences on end-of-course evaluation protocols. Feldman (1993) describes the assessment challenges we encounter as distributions of considerations when he argues that responses to survey questions provide only an estimate of the central tendency of an individual's attitude or belief about a subject or object. Craig and Martinez (2005) summarize the issue: "in retrospect, it seems rather simplistic to think of attitudes as always being unidimensional. After all, who hasn't experienced mixed feelings about people, places and things that we have encountered or visited in our lives?” (p. 1)

\section{Recent Studies on Student Satisfaction with Online Courses}

Multiple approaches define and assess student satisfaction. Rubin, Fernandes \& Avgerinou (2013) extended research on the Community of Inquiry (Garrison, Anderson \& Archer, 2000) which defines social, cognitive, and teaching presence as being essential to the student learning experience and, thus, student satisfaction. They determined that learning management system (LMS) features greatly impact perceptions of community according to the inquiry framework. In a related study, Mahmood, Mahmood and Malik (2012) argued that teaching presence plays the most critical role in how students evaluate online learning.

The interaction construct plays an important role in both face-to-face and online learning modalities (Kuo, Walker, Belland \& Schroder, 2013). In fact, many studies have found that both quantity and quality of student interactions are highly correlated with student satisfaction in almost any learning environment. However, investigators have noted that demographic and cultural considerations also impact the design of appropriate interaction techniques in online learning (González-Gómez, Guardiola, Martín Rodríguez \& Montaro Alonso, 2012).

Ke and Kwak (2013) identified five elements of student satisfaction: learner relevance, active learning, authentic learning, learner autonomy, and technology competence. Kuo et al. (2013) determined that learner-instructor interaction and learner-content interaction combined with technology efficacy are valid indicators of students' positive perceptions. However Battalio (2007), using a criterion approach, argued that a positive course rating requires effective learner-instructor interaction.

Keengwe, Diteeyont and Lawson-Body (2012) argued that students' expectations influence the instructor's design of effective technology tools in online courses and are the key to understanding the satisfaction construct. The authors concluded that satisfaction was most impacted by learning convenience combined with the effectiveness of e-learning tools. Dziuban, Moskal, Brophy-Ellison and Shea (2007) found six key elements that contribute to students' satisfaction: an enriched learning 
environment, well-defined rules of engagements, instructor commitment, reduced ambiguity, an engaging environment, and reduced ambivalence about the value of the course.

Because colleges and universities have to be much more responsive to their student client base (Long, 2011; Bordelon, 2012; Allen \& Seaman, 2013), ambivalence becomes particularly important. This implies satisfaction is an underlying indicator of success in various learning environments, especially online modalities. Satisfied students appear to be engaged, motivated and responsive; contribute to an effective learning climate; and achieve at higher levels. Dissatisfied or ambivalent students contribute to environments where instructors appear to have much more difficulty facilitating effective learning situations. Faculty members in such circumstances have trouble relating to their students and may incorrectly assume that such difficulties are related primarily to student dissatisfaction with online learning (Dziuban et al., 2007).

A precise configuration of student satisfaction with online learning is proving to be elusive because it might be context dependent (e.g., college, discipline, course level, institution, and, of course, instructor). Bowker and Star (1999) use the term "boundary object" to suggest that these items or ideas adapt to specific needs and constraints while maintaining a common identity. While bringing a community of practice together for communication and inquiry purposes, they are generally are weak in the large cohort. According to these researchers, however, the object (student satisfaction, in this case) is much more well-defined within individual constituencies. These definitional issues appear to reflect what Watts (2011) calls confirmation bias - that is, accepting information that confirms our existing beliefs much more readily than information that does not. To express their degree of satisfaction, students react only to things that they expect, but are never expressly stated (i.e., their predetermined psychological contract) or to what they have already assumed about the course. However, should dissonance with these expectations develop, students may encounter ambivalence characterized by simultaneous positive and negative feelings. These are the mixed emotions described by Weigert (1991) and Long (2011).

\section{Factor Studies of Student Satisfaction with Online Learning}

A small number of studies conducted by investigators seeking to identify the dimensionality of student satisfaction with online learning have emerged in the past few years. This work has been a natural extension of inquiry into student satisfaction in higher education (Abrami \& d'Apollonia, 1991; Feldman, 1976; Feldman, 1993; Greenwald \& Gilmore, 1997; Kim, Damewood \& Hodge, 2000; Marsh \& Roche, 1997; McKeachie, 1997). While prior studies have focused primarily on face-to-face teaching environments, online learning has provided a new dynamic and has re-energized interest in the topic. Arbaugh (2007) adopted factoring methods to validate the Community of Inquiry framework (Garrison et al., 2000) incorporating social, cognitive, and teaching presences. He retrieved these primary constructs and demonstrated that they exhibited excellent reliability. His work extended the original Community of Inquiry framework to a fourth dimension: course design and organization. Stewart, Hong, and Strudler (2004), using principal components analysis, found a fairly complex underlying dimensionality that defines the pattern of student satisfaction in online learning: the evaluative construct for student involved issues such as web page appearance, hyperlinks and navigation facility, technical constraints, online applications, instructional techniques and expectations, content delivery, and the interaction environment. Bangert (2006) found four underlying elements related to the evaluation of online and blended courses: interaction, active learning, time on task, and student cooperation. In a later study, he validated his previous findings using both exploratory and confirmatory factor methods (Bangert, 2008).

In a somewhat different approach to the identification of underlying dimensionality, Wang, Dziuban, Cook, and Moskal (2009) used classification and regression trees to predict student assessment of online courses and identified a series of validated if-then decision rules for predicting students' perceptions of excellent teaching based on three constructs: facilitation of learning, ability of the instructor to communicate information and concepts, and the instructor's respect and concern for students.

Dziuban and Moskal (2011) conducted a study of the factor invariance in student satisfaction across online, blended, and face-to-face courses. Using Guttman’s (1954) image analysis, they found a single general component that remained constant across all modalities. The authors concluded that 
students do not use the modality of a course to differentiate elements of excellent instruction and course satisfaction.

In a later study, Dziuban, Moskal, Kramer and Thompson (2013) used the alpha factoring procedure (Kaiser \& Caffery, 1965) to identify the underlying dimensionality of satisfaction under varying conditions of student ambivalence toward their online courses. Using overall satisfaction with the course, they classified students into five categories: negative non-ambivalent, negative ambivalent, ambivalent, positive ambivalent and positive non-ambivalent, corresponding with the 5-item Likert scale. By factoring the remaining items of the instrument stratified by those categories, they found the highest dimensionality for students in the ambivalent categories and the lowest dimensionality in the nonambivalent classifications. The factors in the extreme categories (either positive or negative) were identical as were the factors in the positive ambivalent and negative ambivalent categories. The authors hypothesized that the students who appear to be least engaged in their courses (i.e., ambivalent) may be the most reflective and thoughtful about evaluating their educational experience.

\section{Psychological Contracts as a Basis for Understanding Satisfaction}

By definition, factor analysis studies imply latent dimensions-constructs that cannot be directly observed. Therefore, the underlying components identified in these kinds of studies relate closely to Argyris's (1960) notion of a psychological contract. These contracts are formed by implicit understanding and are not bound by written or legal agreements of two parties within a reciprocal relationship. They consist of perceived obligations and expectations, and thus, are subjective and vary from person to person (Bordia, Hobman, Restubog, \& Bordia, 2010). When broken, or breached, (due to perceived unfairness, inequality, or mistrust), satisfaction and performance decline and workforce turnover increases, consequently impacting attitudes and behaviors (Bordia et al., 2010).

All workplace psychological contracts contain six features: voluntary choice, mutual agreement, incompleteness, presence of numerous contract makers, plan for managing unsuccessful contract losses, and a relational model between employer and employee (Rousseau, 1990). Relational, transactional and balanced define these six features contained within three different types as outlined by Rousseau (1990). Relational agreements are based on loyalty and stability and, thus, foster satisfaction (Raja, Johns \& Ntalianis, 2004). Transactional agreements include fewer duties, are usually temporary or short in duration, and usually result in behaviors that align or are consistent with the contributions in which one is rewarded. These contributions are economic in nature and viewed as less significant. The balanced agreement: a hybrid contract that is generally open-ended includes a mutual concern between both parties, but with clear expectations (Raja et al., 2004).

When analyzing and assessing psychological contracts, the three forms of measurement include content-oriented assessment, feature and evaluation. The content-oriented assessment examines the obligations of the agreement; the feature-oriented assessment compares one agreement to another's based upon attributes of the contracts; and the evaluation-oriented assessment assesses the degree of fulfillment and the amount of change that results (Rousseau \& Tijoriwala, 1998).

\section{Psychological Contracts in Education}

Although Argyris (1960) developed the theory of a psychological contract for the workplace, the idea has important implications for educational environments. Wade-Benzoni, Rousseau, and Li (2006), for instance, contend that students view psychological contracts as a form of mutual exchange in the education process. The interactions between student and instructor are crucial and telling about ongoing perceptions of obligations (Wade-Benzoni et al., 2006). Often there is little to no explicit communication about these arrangements because they are informal and temporary. The power in the relationship within these contracts is predominately asymmetric, favoring faculty members who hold expectations about student performance and control resources such as grades, letters of recommendation, advice on careers, and, in some cases, dissertation research approval (Wade-Benzoni et al., 2006).

Prior to viewing a syllabus, students begin to form expectations as they assess course offerings for academic development, decision-making input, challenges, feedback, and support (Spies et al., 2010). 
According to Spies et al. (2010), students pay close attention to the following categories: faculty, futuristic factors, student development, course and curricular content, learning opportunities, involvement, and facilities. These agreements tend to change and become more elaborate as the course progresses.

Within a particular class, both students and faculty form a large number of contracts that present satisfaction challenges if, in the participants' judgment, their implicit expectations are not met. This suggests that student satisfaction with online learning is, as Lakoff (1987) termed, a function of an idealized cognitive model-a construct fabricated to bring clarity and structure to a situation. Kahneman (2011) describes this thinking as "what you see is all there is." Because of the complex interaction of these many constructs, however, student satisfaction with online learning appears to be an example of "there is much more than you can see directly."

\section{The Survey and Sample}

The Research Initiative for Teaching Effectiveness (RITE) at the University of Central Florida (UCF) has been surveying UCF's online students as part of an ongoing impact evaluation since 1996, when the university began offering Web courses. The longitudinal nature of the university's examination of student attitudes has allowed for refinement and validation from the original survey. Ongoing evaluation allows researchers to accommodate rapid change in the online course environments and provide baseline data on items that may contribute to student satisfaction with these courses (Roberts, 2007).

Response rates for online surveys are always a concern (Sax, Gilmartin \& Bryant, 2003). The art of a student survey is the development of an instrument that addresses the target, yet requires a minimal time to complete. The current RITE instrument focuses specifically on the dynamics of student satisfaction with online learning and is presented in a 5-point Likert scale format, ranging from strongly agree to strongly disagree. Items related to the learning management system or to technology itself have been excluded in an effort to minimize survey fatigue. Survey items were validated by examining their psychometric properties from previous surveys in terms of central tendency, variability, skewness and kurtosis, looking for anomalies, and for their relevance to the current state of the online initiative.

Once the original item pool was selected the survey was developed using Google Forms (https://drive.google.com). Students were sent an announcement through the UCF Knights student email platform. Student directions included the purpose of the study, their rights as survey participants, and contact information for both the survey administrators and the University's Institutional Review Board. Students were advised that the survey was open only to undergraduates 18 years of age and older, and were reminded that the survey was voluntary. Students were free to omit any question they were not comfortable answering or stop at any time with no penalty. Students received no rewards for participation and there were no risks for non-participation. All student data remained anonymous when aggregated. Overall 1,217 surveys were returned.

An examination of student responses indicated that $84 \%$ of students represented the millennial generation, $72 \%$ were female, and $76 \%$ were unmarried. Almost half of the responding students worked at least 10 hours per week and data reflected the ethnic demography of the university, with $70 \%$ of students having a grade point average of at least 3.0. Respondents were experienced with online learning-97\% of students indicated taking at least one online course, with a median of five online courses. Students were predominately upperclassmen, with $83 \%$ of respondents being juniors or seniors. The university has targeted the majority of its online offerings to the upper undergraduate level, thereby allowing for the transition of freshmen and sophomores to university life prior to extensive online learning. Our respondent sample of predominately upper undergraduates reflects this philosophy. Students who indicated they had not taken an online course were excluded from analyses, reducing the usable sample to 1,197 responses. 


\section{Methodology}

\section{Reliability and Domain Sampling}

Prior to any analysis of the item responses collected in this sample, the psychometric quality of the information yielded by the instrument was assessed with validated techniques. Next, coefficient alpha (Cronbach, 1951) was used to determine the survey reliability. The psychometric sampling issue of how well the items comprise a reasonable sample from the domain of interest is an important aspect of analyzing constructs such as student satisfaction. Addressing this issue, Guttman (1953) developed a theoretical solution illustrating that the domain sampling properties of items improve when the inverse of the correlation matrix approaches a diagonal. Kaiser and Rice (1974) used this property to develop their measure of sample adequacy. The index has an upper bound of one with Kaiser offering some decision rules for interpreting the value of measure of sampling adequacy (MSA). If the value of the index is in the range .80 to .99 , the investigator has evidence of an excellent domain sample. Values in the .70s signal an acceptable result, and those in the .60s indicate data that are unacceptable. MSA has been used for data assessment prior to the application of any factoring procedures. Computation of the MSA index gives the investigators a benchmark for the construct validity of the items. This procedure was recommended by Dziuban and Shirkey (1974) prior to any latent dimension analysis. An individual MSA for each variable gives the investigators an indication of whether or not a particular item belongs in the particular domain.

\section{Dimensionality of Student Responses}

The investigators sought to determine whether multiple dimensions underlie students' satisfaction to their online learning environments. This is normally accomplished by the application of some version of the generalized factor analysis procedure. In this study the data were analyzed with Guttman's (1954) image analysis. The procedure assumes that the data sets divide into two components. The first component is the portion of data that can be predicted from the remaining variables in the set (the image). The second component is the data that is not predictable from the remaining variables (the anti-image). The method is operationalized by predicting a standardized score on a variable for each individual from the remaining variables in the set. The image procedure derives underlying components found in the covariance matrix (the image matrix) of the standardized variables.

The number of factors (components) retained in the final solution was determined by a procedure originally proposed by Dziuban and Shirkey (1993) and later validated by Hill (2011). The method involves the initial assessment of the dataset with the MSA followed by subsequent MSA computation on the matrix of partial correlations once the impact of the first, second, third etc. number of factors have been removed from the system. Once a value in the .60s has been reached, the majority of information from the system has been attained. The initial pattern matrix was transformed (rotated) according to the promax (Hendrickson \& White, 1964) procedure. Pattern coefficients absolutely larger than .40 were used for interpretation purposes (Stevens, 2002).

Once the final dimensionality of the data set was determined, factor scores for each subject in the sample were derived using the Anderson and Rubin (1956) method. These scores have a mean of zero and a standard deviation of one and are uncorrelated with each other. They also have a reasonably good relationship to the estimated factor validity. The final step in the handling of the data involved deriving a linear transformation of the standardized factor scores with $\mathrm{T}=(\mathrm{Z} \times 10)+50$ giving the scores a mean of 50 and standard deviation of 10 for ease of interpretation.

The scores for each factor were used as dependent measures for a rescaled comparison variable related to overall online course satisfaction. Because the number of dissatisfied students was small, the comparison variable was declassified into satisfied, ambivalent, and dissatisfied and used as a factor in the hypothesis test. The investigators were concerned with trends and effect size differences among the dissatisfied (4\%), ambivalent (5\%), and satisfied (91\%) groups followed by Bonferroni post hoc comparisons (Hochberg, 1988). 


\section{Results}

The promax transformed pattern matrix may be found in Table 1. The overall MSA for the variables set was .94 with an overall alpha reliability coefficient of .96. These values indicate excellent domain sampling and reliability. The individual MSAs indicate each item belongs to the family psychometrically. Upon extraction of three dimensions from the system using the Dziuban-Shirkey procedures, the MSA on the residual correlation matrix was .58 indicating that what remained in the system was essentially noise.

Table 1 Pattern Matrix for the Promax Transformed Image Analysis

\begin{tabular}{|c|c|c|c|c|}
\hline Items & $\begin{array}{l}\text { Engaged } \\
\text { Learning }\end{array}$ & Agency & Assessment & MSA \\
\hline $\begin{array}{l}\text { Generally, I am more engaged in my online } \\
\text { courses }\end{array}$ & .84 & .04 & -.07 & .94 \\
\hline $\begin{array}{l}\text { I have more opportunities to reflect on what I } \\
\text { have learned in online courses }\end{array}$ & .79 & -.05 & .04 & .94 \\
\hline $\begin{array}{l}\text { Online learning helps me understand course } \\
\text { material }\end{array}$ & .76 & .03 & .05 & .95 \\
\hline $\begin{array}{l}\text { There are more opportunities to collaborate } \\
\text { with other students in an online course }\end{array}$ & .67 & -.14 & -.03 & .93 \\
\hline $\begin{array}{l}\text { My online experience has increased my } \\
\text { opportunity to access and use information }\end{array}$ & .66 & .11 & .06 & .95 \\
\hline $\begin{array}{l}\text { I am more likely to ask questions in an online } \\
\text { course }\end{array}$ & .65 & -.11 & .01 & .94 \\
\hline $\begin{array}{l}\text { Generally, I understand course requirements } \\
\text { better in an online course }\end{array}$ & .64 & -.09 & .19 & .96 \\
\hline $\begin{array}{l}\text { Because of online courses, I am more likely to } \\
\text { get a degree }\end{array}$ & .56 & .09 & -.03 & .94 \\
\hline $\begin{array}{l}\text { I can manage my own learning better in online } \\
\text { courses }\end{array}$ & .54 & .18 & .17 & .95 \\
\hline Take more online courses? & .47 & .22 & .04 & .96 \\
\hline I am motivated to succeed & -.12 & .56 & -.03 & .81 \\
\hline I have strong time management skills & .05 & .53 & -.07 & .85 \\
\hline I am a multitasker & -.05 & .57 & .05 & .87 \\
\hline $\begin{array}{l}\text { Assessment of my academic progress is more } \\
\text { accurate in online courses }\end{array}$ & -.19 & -.04 & .56 & .92 \\
\hline $\begin{array}{l}\text { I can more easily monitor my academic } \\
\text { progress in online courses }\end{array}$ & .14 & .11 & .51 & .92 \\
\hline $\begin{array}{l}\text { Response time from teachers and assistants is } \\
\text { quicker in online courses }\end{array}$ & .24 & -.12 & .43 & .94 \\
\hline $\begin{array}{l}\text { MSA }=.94 \\
\text { Residual MSA = .58 } \\
\text { Average Item Correlation }=.70 \\
\alpha=.96\end{array}$ & & & & \\
\hline
\end{tabular}

From Table 1, the reader may observe that the first factor appears very general, covering a number of issues associated with online courses ranging from engagement through willingness to take 
another online course. However, upon closer examination, it is clear what appears to be very general is quite specific in relation to what students evaluate in online courses. These elements include students' abilities to engage, reflect, understand material, collaborate, find information, question, understand course requirements, manage their own learning, and increase opportunities for degree completion. This finding suggests students simultaneously evaluate multiple aspects of online courses to make decisions about their class experience. Furthermore, students may evaluate each element separately, especially when they are unsure of their satisfaction levels. We name this factor engaged learning (74\% factor variance) and in many respects, it conforms to Tolstoy's (1878/2004) opening argument and Diamond's (1999) contention that many elements must be accommodated if conditions are to be resolved satisfactorily. Conversely, any one or more of these elements might cause students to be less than satisfied with their educational experience.

The second factor (17\% factor variance) in the pattern matrix involves motivation, time management skills, and multitasking ability. This dimension suggests that students' sense of agency-that is, students' ability to initiate and control their own actions in the learning environment-plays a role in their satisfaction with their online learning experience. Students with a strong sense of agency assume responsibility for their learning and bring a sense of empowerment to their classes. Since the majority of students in this study indicated higher levels of satisfaction with online learning, we might reasonably assume they bring a higher sense of agency as well. Agency, however, may not be specifically related to course modality.

The final factor (9\% factor variance) depicts the manner in which the assessment process evolves in the online environment. Satisfied students are characterized by an ability to assess and monitor their progress, and indicate that a timely response by the instructor plays an important role in their satisfaction. Therefore, we find online students incorporate three dimensions into their evaluation process of online learning experiences: 1) engaged learning with various course elements, 2) a sense of agency, and 3) an efficient assessment of academic progress.

The factor correlation matrix in Table 2 indicates that these student dimensions are highly and positively related in a generally satisfied population. This suggests that engaged learning, agency, and assessment factors form a highly interrelated lexicon for student satisfaction, with engaged learning most highly related to agency $(r=.86)$ and agency most highly related to assessment $(r=.77)$.

Table 2 Factor Correlation Matrix

\begin{tabular}{lll}
\hline Factors & $\begin{array}{l}\text { Engaged } \\
\text { Learning }\end{array}$ & Agency \\
\hline Engaged Learning & & \\
Agency & .86 & \\
Assessment & .59 & .77 \\
\hline
\end{tabular}

The average correlation among the factors in Table 3 is .74 when computed by the method developed by Kaiser (1958). Table 3 contains the means, standard deviations, and significance levels for the three sets of factor scores for the declassified overall satisfaction variable. In addition, the table contains the pairwise combinations that proved significant on the Bonferroni comparison and the associated effect size calculated by the method outlined by Hedges and Olkin (1985). The factor scores for engaged learning and agency lead to the null hypothesis rejection, however assessment did not. For 
engaged learning, dissatisfied versus ambivalent ratings produced an effect size of .53, dissatisfied versus satisfied ratings yielded values of 2.01, and ambivalent versus satisfied ratings equaled 1.43. Bonferroni comparisons for the agency factors showed two significant differences with dissatisfied versus satisfied ratings producing an effect size value of 1.03, while ambivalent versus satisfied ratings yielded .77. Each of the above effects sizes by most standards is considered substantial.

Table 3 Factor Score Difference by Overall Satisfaction

\begin{tabular}{|c|c|c|c|c|c|c|c|}
\hline \multirow[b]{2}{*}{ Factors Scores } & \multicolumn{2}{|c|}{$\begin{array}{l}\text { Dissatisfied (D) } \\
(\mathrm{n}=46)\end{array}$} & \multicolumn{2}{|c|}{$\begin{array}{l}\text { Ambivalent (A) } \\
(n=56)\end{array}$} & \multicolumn{2}{|c|}{$\begin{array}{l}\text { Satisfied (S) } \\
(n=1016)\end{array}$} & \multirow[b]{2}{*}{ Sig } \\
\hline & $\bar{x}$ & S.D. & $\bar{x}$ & S.D. & $\bar{x}$ & S.D. & \\
\hline Engaged Learning & 33.63 & 10.86 & 38.92 & 8.92 & 51.59 & 8.86 & .00 \\
\hline Agency & 41.46 & 11.27 & 43.74 & 13.84 & 50.98 & 9.15 & .00 \\
\hline Assessment & 48.93 & 9.24 & 49.21 & 8.56 & 50.13 & 10.19 & .63 \\
\hline
\end{tabular}

Significant Bonferroni Pairwise Differences

\begin{tabular}{lccc}
\hline Categories & Engaged Learning & Agency & Assessment \\
\hline Dissatisfied vs. Ambivalent & .00 & $\mathrm{~ns}$ & $\mathrm{~ns}$ \\
Dissatisfied vs. Satisfied & .00 & .00 & $\mathrm{~ns}$ \\
Ambivalent vs. Satisfied & .00 & .00 & $\mathrm{~ns}$ \\
\hline
\end{tabular}

Effect Sizes - Hedges' $g$

\begin{tabular}{lccc}
\hline Categories & Engaged Learning & Agency & Assessment \\
\hline Dissatisfied vs. Ambivalent & 0.53 & 0.18 & 0.03 \\
Dissatisfied vs. Satisfied & 2.01 & 1.03 & 0.12 \\
Ambivalent vs. Satisfied & 1.43 & 0.77 & 0.09 \\
\hline
\end{tabular}

\section{Limitations}

There are a number of limitations in this study. Initially it should be noted that the factors derived resulted from a one-time administration of the survey instrument during the semester. Therefore, the stability of the satisfaction factors over an entire semester has not been validated. Second, the study was conducted on individual item responses rather than scales. Although this has precedent in literature, single items with presumed low reliability can be problematic in factor studies such as this because of their instability. Third, many aspects of exploratory factor analysis involve arbitrary decisions, for instance, number of factors to extract, values for salience in the pattern matrix, rotational strategy, and naming the final dimensions. Fourth, online survey research using mass e-mailings to students has the possibility of introducing response bias into the data. This makes replication of studies much more difficult. Finally, although the investigators collected extensive demographic data on the responding students, there was no possibility for controlling for many of the student characteristics that might have influenced the results. This raises a more general limitation resulting from the ease with which survey instruments can be distributed in the electronic environment. This causes many students to suffer "survey fatigue" that can adversely impact response rates. 


\section{Conclusion}

\section{Student Satisfaction in the Online Environment}

From its inception, the Sloan-Consortium (now the Online Learning Consortium) established student satisfaction with online leaning as one of its founding metaphoric pillars. In doing so, the organization demonstrated a commitment to the student voice as a component for understanding effective teaching and learning. This commitment by the Online Learning Consortium resulted in two decades of research devoted to understanding how students define excellence in their learning space. Satisfaction with online learning is becoming increasingly important in higher education for a number of reasons. The most important is the rapid adoption of this teaching and learning modality in colleges, universities, and community colleges across the country. However, another mediating issue is the growing sense of student agency in the educational process. Students are able and do express their opinions about their educational experiences in formats ranging from end of course evaluation protocols to social networks of all varieties making their voice more important than ever before.

\section{Factor Studies}

Online learning has redefined student satisfaction research. It has caused the education research community to reexamine traditionally held assumptions that learning primarily takes place within a metaphoric container called a "course." In reviewing the studies that address student satisfaction, from a factor analytic perspective, one point becomes obvious: this is a complex system with very little agreement. Even the most recent factor analytic studies have done little to resolve the lack of consensus about the dimensions that underlie satisfaction with online learning. This appears to be the factor invariance problem in full bloom, where differing contexts mediate how students relate to their learning experiences because a common prototype for online courses has been elusive at best. There exists the possibility that each course incorporates several unique characteristics that make it difficult to identity common factors that are robust across context. Although the results of these studies differ in how many and what dimensions constitute satisfaction, their unifying objective was the same: identify the underlying theoretical perspective of student perception of online learning. In addition, all of them subscribed to latent trait theory, recognizing that the important dimensions that students differentiate when they express their opinions about online learning are formed by the combination of the original items that cannot be directly observed - that which underlies student satisfaction.

\section{Psychological Contracts as a Lens for Student Satisfaction}

Very often theories developed in on one discipline inform work in another area. We contend that this is the case with the psychological contracts and factors that define student satisfaction with online learning. The theory of psychological contracts explains employee satisfaction through the perspectives of expectations for the work place and employee interactions. These contracts may be common across employees, for instance safety on the job, or they may be unique to individual employees such as promotion. The elements of the contract are implicit in that they are never formally stated, but they are assumed by the individual holding them to be mutually agreed upon between the employee and the employer. Of course, this may or may not be so. Most importantly, a violation of the psychological contract, either real or perceived, by either party, leads to workplace dissatisfaction.

In factor analytic studies, items about student satisfaction with online learning correspond to the formation of a psychological contract. The survey responses are reconfigured into a smaller number of latent (non-observable) dimensions that are never really articulated by the students, but are, nonetheless, fully expected to be satisfied. Of course, instructors have contracts for students as well. Studies such as this identify the student psychological contact after the fact, not prior to the class, however, nothing prevents both from happening and/or a comparison of the two. The prior contract might be identified before the class and the satisfaction factors after the class. 
Student Satisfaction with Online Learning: Is it a Psychological Contract?

Table 4 Correspondence Between Satisfaction and Psychological Contracts

\begin{tabular}{llll}
\hline $\begin{array}{l}\text { Student Satisfaction } \\
\text { Factors }\end{array}$ & Student Voice & Contract Features & Contract Assessment \\
\hline Engaged Learning & $\begin{array}{l}\text { "Facilitate my learning” } \\
\text { "Recognize my abilities and } \\
\text { Agency }\end{array}$ & Relational & Evaluation Oriented \\
Assessment & "Let me know where I stand” & Transactional & Content Oriented \\
\hline
\end{tabular}

Table 4 depicts the relationship between online student satisfaction factors and the features of a psychological contract specified in the literature. Each factor translates into how it might be expressed in the student voice followed by a corresponding contract feature and an assessment strategy. Engaged learning, the largest contributor to the factor pattern, indicates that students expect instructors to adopt a facilitative role in their teaching. This dimension corresponds to the relational contract where the learning environment is stable and organized with a clearly delineated path to success. Assessment in this situation is evaluation oriented, indexing fulfillment and change (i.e., students achieving learning outcomes).

The second factor, agency, characterizes satisfied students who recognize their abilities and accomplishments in a balanced contract arrangement that they assessed by the degree of agreement between them and the instructor (feature oriented). The final factor, assessment, corresponds to that transactional contract with its evaluation determined by the degree to which the obligations of the course have been met (content oriented).

Although they have been developed in different contexts, workplace contracts and student satisfaction factors are similar. Both attempt to explain the underlying cause of satisfaction or lack thereof. Both are general and non-nonspecific, becoming more complex as the job, class, or classes evolve over time. They are limited in their scope and at best index a kind of average perception of the workplace or educational environment. Rarely are employees fully satisfied with their jobs or students completely satisfied with their classes. However, both contracts and factors frame blueprints for developing instructional design strategies that can improve learning climates. Online learning has unbundled the classroom and the same technologies have done precisely the same to the workplace: no longer are either bound by physical space.

Perhaps in a more traditional time, psychological contracts (predispositions) and student satisfaction elements (post dispositions) were somewhat separate in their context and orientation. However, it seems clear that information and instructional technologies are migrating into the same orientation space. This makes the questions "What did you expect on your way in?" and "Now that you are finished, how was your experience?” part of the same climate assessment paradigm. By coalescing factors and psychological contracts, we might gain insights into more effective learning environments that are not possible when each theory is considered separately. Blending the two takes best features of both and results in something entirely new--something more than you can see in either theory. 


\section{References}

Abrami, P.C., \& d'Apollonia, S. (1991). Multidimensional students' evaluations of teaching effectiveness-generalizability of " $\mathrm{N}=1$ " research: Comment of marsh. Journal of Educational Psychology, 83(3), 411-415. doi: 10.1037/0022-0663.83.3.411

Akdemir, O., \& Koszalka, T. A. (2008). Investigating the relationships among instructional strategies and learning styles in online environments. Computers \& Education,50(4), 1451-1461. doi: 10.1016/j.compedu.2007.01.004

Allen, I. E., \& Seaman, J. (2013). Changing course: Ten years of tracking online education in the United States. Newburyport, MA: Sloan Consortium.

Anderson, R. D., \& Rubin, H. (1956). Statistical inference in factor analysis. Proceedings of the Third Berkeley Symposium of Mathematical Statistics and Probability, 5, 111-150.

Arbaugh, J.B. (2007). An empirical verification of the community of inquiry framework. Journal of Asynchronous Learning Network, 11(1), 73-85.

Arbaugh, J. B. (2001). How instructor immediacy behaviors affect student satisfaction and learning in web-based courses. Business Communication Quarterly, 64(4), 42-54. doi: 10.1177/108056990106400405

Argyris, C. (1960). Understanding organizational behavior. Homewood, IL: Dorsey.

Bangert, A. W. (2006). Identifying factors underlying the quality of online teaching effectiveness: An exploratory study. Journal of Computing in Higher Education, 17(2), 79-99. doi: 10.1007/BF03032699

Bangert, A. W. (2008). The development and validation of the student evaluation of online teaching effectiveness. Computers in the Schools, 25(1), 35-47. doi: 10.1080/07380560802157717

Battalio, J. (2007). Interaction online: A reevaluation. Quarterly Review of Distance Education, 8(4), 339352.

Bolliger, D. U. (2004). Key factors for determining student satisfaction in online courses. International Journal on E-Learning, 3(1), 61-67.

Bordelon, D. E. (2012). Where have we been? Where are we going? The evolution of American higher education. Procedia-Social and Behavioral Sciences, 55(5), 100-105. doi: 10.1016/j.sbspro.2012.09.483

Bordia, S., Hobman, E. V., Resubog, S. L. D., \& Bordia, P. (2010). Advisor-student relationship in business education project collaborations: A psychological contract perspective. Journal of Applied Social Psychology, 40(9), 2360-2386. doi: 10.1111/j.1559-1816.2010.00662.x

Bowker, G. C., \& Star, S. L. (1999). Sorting things out: Classification and its consequences. Cambridge, MA: The MIT Press.

Carnaghan, C., \& Webb, A. (2007). Investigating the effects of group response systems on student satisfaction, learning, and engagement in accounting education. Issues in Accounting Education, 22(3), 391-409. doi: http://dx.doi.org/10.2308/iace.2007.22.3.391

Craig S. C. \& Martinez M. D. (2005). Ambivalence and the structure of political opinion. New York: Palgrave Macmillian.

Cronbach, L. J. (1951). Coefficient alpha and the internal structure of tests. Psychometrika, 16(3), 297334. doi:10.1007/BF02310555

Diamond, J. (1999). Germs, guns, and steel: The fates of human societies. New York: W. W. Norton \& Company, Inc.

Dziuban, C., \& Dziuban, J. (1998). Reactive behavior patterns in the classroom. Journal of Staff, Program \& Organization Development, 15(2). 85-31. 
Dziuban, C., McMartin, F., Morgan, G., Morrill, J., Moskal, P., \& Wolf, A. (2013). Examining student information seeking behaviors in higher education. Journal of Information Fluency, 2(1), 36-54.

Dziuban, C., \& Moskal, P. (2011). A course is a course is a course: Factor invariance in student evaluation of online, blended and face-to-face learning environments. The Internet and Higher Education, 14(4), 236-241. doi: 10.1016/j.iheduc.2011.05.003

Dziuban, C., Moskal, P., Brophy-Ellison, J., \& Shea, P. (2007). Student satisfaction with asynchronous learning. Journal of Asynchronous Learning Networks, 11(1), 87-95.

Dziuban, C. D., Moskal, P. D., \& Dziuban, E. K. (2000). Reactive behavior patterns go online. The Journal of Staff, Program \& Organizational Development, 17(3), 155-179.

Dziuban, C.D., Moskal, P.D., Juge, F., Truman-Davis, B., Sorg, S. \& Hartman, J. (2003). Developing a web-based instructional program in a metropolitan university. In B. Geibert \& S. H. Harvey (Eds.), Web-wise learning: Wisdom from the field (pp. 47-81). Philadelphia, PA: Xlibris Publications.

Dziuban, C., Moskal, P., Kramer, L., \& Thompson, J. (2013). Student satisfaction with online learning in the presence of ambivalence: Looking for the will-o'-the-wisp. Internet and Higher Education, 17, 1-8. doi: 10.1016/j.iheduc.2012.08.001

Dziuban, C. D., \& Shirkey, E. C. (1974). When is a correlation matrix appropriate for factor analysis? Some decision rules. Psychological Bulletin, 81(6), 358-361. doi: 10.1037/h0036316

Dziuban, C. D., \& Shirkey, E. C. (November, 1993). S.D. 50-A sequential psychometric criterion for the number of common factors. Presented at The Annual Conference for Florida Educational Research Association, Destin, Florida.

Feldman, K. A. (1976). The superior college teacher from the student's view. Research in Higher Education, 5, 243-288. doi: 10.1007/BF00991967

Feldman, K. A. (1993). College students' views of male and female college teachers: Part II- evidence from students' evaluation of their classroom teachers. Research in Higher Education, 34(2), 151191. doi:10.1007/BF00992161

Garrison, D. R., Anderson, T., \& Archer, W. (2000). Critical inquiry in a text-based environment: Computer conferencing in higher education. The Internet and Higher Education, 2(2), 87-105. doi: 10.1016/S1096-7516(00)00016-6

González-Gómez, F., Guardiola, J., Martín Rodríguez, Ó., \& Montero Alonso, M. Á. (2012). Gender differences in e-learning satisfaction. Computers \& Education,58(1), 283-290. doi: 10.1016/j.compedu.2011.08.017

Greenwald, A.G., \& Gilmore, G. M. (1997). Grading leniency is a removable contaminant of student ratings. American Psychologist, 52(11), 1209-1217. doi: 10.1037/0003-066X.52.11.1209

Guttman, L. (1953). Image theory for the structure of quantitative variates. Psychometrika, 18, 277-269. doi:10.1007/BF02289264

Guttman, L. (1954). Some necessary conditions for common factor analysis. Psychometrika, 19, 149-161. doi:10.1007/BF02289162

Hedges, L.V., \& Olkin, I. (1985). Statistical methodology in meta-analysis. San Diego, CA: Academic Press.

Hendrickson, A. E., \& White, P. O. (1964). Promax: A quick method for rotation to oblique simple structure. British Journal of Statistical Psychology, 17(1), 65-70. doi: 10.1111/j.20448317.1964.tb00244.x

Hill, B. D. (2011). The sequential Kaiser-Meyer-Olkin procedure as an alternative for determining the number of factors in common-factor analysis: A Monte Carlo simulation Doctoral dissertation, Oklahoma State University. 
Hochberg, Yosef (1988). A sharper bonferroni procedure for multiple tests of significance. Biometrika, 75(4): 800-802. doi:10.1093/biomet/75.4.800.

Kahneman, D. (2011). Thinking, fast and slow. New York: Farrar, Strauss, Giroux.

Kaiser, H. F. (1958). The varimax criterion for analytic rotation in factor analysis. Psychometrika, 23(3), 187-200. doi:10.1007/BF02289233

Kaiser, H., \& Caffrey, J. (1965). Alpha factor analysis. Psychometrika, 30(1), 1-14. doi:10.1007/BF02289743

Kaiser, H. F., \& Rice, J. (1974). Little jiffy, mark IV. Journal of Educational and Psychological measurement, 34(1), 111-117. doi: 10.1177/001316447403400115

Ke, F., \& Kwak, D. (2013). Constructs of student-centered online learning on learning satisfaction of a diverse online student body: A structural equation modeling approach. Journal of Educational Computing Research, 48(1), 97-122. doi: 10.2190/EC.48.1.e

Keengwe, J., Diteeyont, W., \& Lawson-Body, A. (2012). Student and instructor satisfaction with elearning tools in online learning environments. International Journal of Information and Communication Technology Education (IJICTE), 8(1), 76-86. doi:10.4018/jicte.2012010108

Kim, C., Damewood, E., \& Hodge, N. (2000). Professor attitude: Its effect on teaching evaluations. Journal of Management Education, 24(4), 458-473. doi:10.1177/105256290002400405

Kuo, Y. C., Walker, A. E., Belland, B. R., \& Schroder, K. E. (2013). A predictive study of student satisfaction in online education programs. The International Review of Research in Open and Distance Learning, 14(1), 16-39.

Lakoff, G. (1987). Women, fire, and dangerous things. Chicago: University of Chicago Press.

Liu, G. Z., \& Hwang, G. J. (2010). A key step to understanding paradigm shifts in e-learning: towards context-aware ubiquitous learning. British Journal of Educational Technology, 41(2), E1-E9. doi: $10.1111 / \mathrm{j} .1467-8535.2009 .00976$.

Long, W. A. (2011). Your predictable adolescent. Charleston, SC: BookSurge Publishing.

Mahmood, A., Mahmood, S. T., \& Malik, A. B. (2012). A comparative study of student satisfaction level in distance learning and live classroom at higher education level. Turkish Online Journal of Distance Education (TOJDE), 13(1), 128-136.

Marsh, H. W., \& Roche, L.A. (1997). Making students' evaluations of teaching effectiveness effective: The critical issues of validity, bias, and utility. American Psychologist, 52(11), 1187-1197. doi: 10.1037/0003-066X.52.11.1187

McKeachie, W.J. (1997). Student ratings: The validity of use. American Psychologist, 52(11), 1218-1225.

Norberg, A., Dziuban, C. D., \& Moskal, P. D. (2011). A time-based blended learning model. On the Horizon, 19(3), 207-216. doi: 10.1108/10748121111163913

Raja, U., Johns, G., \& Ntalianis, F. (2004). The impact of personality on psychological contracts. The Academy of Management Journal, 47(3), 350-367. doi: 10.2307/20159586

Richardson, J. C., \& Swan, K. (2003). Examining social presence in online courses in relation to students' perceived learning and satisfaction. Journal of Asynchronous Learning Networks, 7(1), 68-88.

Roberts, C. (2007). The unnatural history of the sea. Washington DC: Island Press.

Rousseau, D. M. (1990). Normative beliefs in fund-raising organizations linking culture to organizational performance and individual responses. Group \& Organization Management, 15(4), 448-460. doi: 10.1177/105960119001500408

Rousseau, D. M. \& Tijoriwala, S. A. (1998). Assessing psychological contracts: Issues, alternatives and measures. Journal of Organizational Behavior, 19, 679-695. doi: 10.1002/(SICI)10991379(1998)19:1+<679::AID-JOB971>3.0.CO;2-N 
Rubin, B., Fernandes, R., \& Avgerinou, M. D. (2013). The effects of technology on the community of inquiry and satisfaction with online courses. The Internet and Higher Education, 17, 48-57. doi: 10.1016/j.iheduc.2012.09.006

Sax, L. J., Gilmartin, S. K., \& Bryant, A. N. (2003). Assessing response rates and nonresponse bias in web and paper surveys. Research in Higher Education, 44(4), 409-432. doi:10.1023/A:1024232915870

Shirky, C. (2010). Cognitive surplus: Creativity and generosity in a connected age. New York: Penguin.

Shirky, C. (2008). Here comes everybody: The power of organizing without organizations. New York: Penguin.

Spies, A. R., Wilkin, N. E., Bentley, J. P., Bouldin, A. S., Wilson, M. C., \& Holmes, E. R. (2010). Instrument to measure psychological contract violation in pharmacy students. American Journal of Pharmaceutical Education, 74(6), 1-11.

Stevens, J.P. (2002). Applied multivariate statistics for the social sciences (4 ${ }^{\text {th }}$ ed.). Mahwah, NJ: Lawrence Erlbaum Associates, Inc.

Stewart, L., Hong, E., \& Strudler, N. (2004). Development and validation of an instrument for student evaluation of the quality of web-based instruction. The American Journal of Distance Education, 18(3), 131-150. doi: 10.1207/s15389286ajde1803_2

Swan, K. (2001). Virtual interaction: Design factors affecting student satisfaction and perceived learning in asynchronous online courses. Distance education, 22(2), 306-331. doi:10.1080/0158791010220208

Tolstoy, L. (2004). Anna Karenina. (R. Pevear \& L. Volokhonsky, Trans.). New York, NY: Penguin. (Original work published 1878).

Wade-Benzoni, K. A., Rousseau, D. M., \& Li, M. (2006). Managing relationships across generations of academics: Psychological contracts in faculty-doctoral student collaborations. International Journal of Conflict Management, 17(1), 4-33. doi: 10.1108/10444060610734154

Wang, M. C., Dziuban, C. D., Cook, I. J., \& Moskal, P. D. (2009). Dr. Fox rocks: Using data-mining techniques to examine student ratings of instruction. In M. C. Shelley, L. D. Yore, \& B. Hand (Eds.), Quality research in literacy and science education: International perspectives and gold standards (pp. 383-398). Dordrecht, Netherlands: Springer. doi:10.1007/978-1-4020-8427-0_19

Watts, D. J. (2011). Everything is obvious. New York: Crown Publishing Group, Random House.

Weigert, A. J. (1991). Mixed emotions: Certain steps toward understanding ambivalence. Albany: State University of New York Press.

Young, B. R., \& Dziuban, E. (2000). Understanding dependency and passivity: Reactive behavior patterns in writing centers. Writing Center Journal, 21(1), 67-87. 